\title{
Analysis of the relationship between MIR155HG variants and gastric Cancer susceptibility
}

Wenjing Zou ${ }^{1,2+}, \mathrm{Xu} \mathrm{Li}^{3 \dagger}$, Cheng Li ${ }^{4}$, Dan Liư ${ }^{5}$, Yanyan LV ${ }^{5}$, Ying Yang ${ }^{6}$, Nan Ye ${ }^{6}$, Dan Guo and Shuixiang He ${ }^{1 *}$

\begin{abstract}
Background: Gastric cancer is one of the most common cancers in the world and a major cause of cancer-related death. This study aims to determine whether genetic variations in MIR155HG could be associated with gastric cancer risk.

Materials \& methods: A total of 506 gastric cancer patients and 500 healthy controls were enrolled in this study. Genotypes were examined with the MassARRAY platform and data management and analysis were conducted with the Typer Software. Odds ratios (OR) and 95\% confidence intervals (Cls) were calculated with logistic regression adjusting for age and gender to evaluate the associations between SNPs with gastric cancer in genetic model analysis.

Results: The "CC" genotype of rs4143370 decreased the risk of gastric cancer in genotype model $(p=0.020)$ and recessive model $(p=0.018)$. Inversely, the "CC" genotype of rs 1893650 increased the risk of gastric cancer in genotype model $(p=0.023)$ and recessive model $(p=0.014)$. Stratified analysis showed that rs 11911469 was associated with an increased risk of gastric cancer only among the male group in the dominant model $(p=0.039)$ and additive model $(p=0.030)$. The haplotype analysis showed a strong linkage disequilibrium among these six SNPs (rs4143370, rs77699734, rs11911469, rs1893650, rs34904192 and rs928883).

Conclusion: This study confirmed the relationship between SNPs of MIR155HG and the gastric cancer risk among the Chinese Han population. Our data may provide a new perspective to understand the aetiology of gastric cancer.
\end{abstract}

Keywords: Gastric cancer, MIR155HG, Single nucleotide polymorphism, Case-control study

\section{Background}

Gastric cancer is rampant all over the world, which brings serious living burden and economic pressure to human beings. Gastric cancer was reported to be the third leading cause of cancer-related mortality [1]. The incidence of this cancer varies by region and ethnicity. In East Asia, the incidence and mortality of gastric cancer are the highest, especially in China [2]. Gastric cancer is a complex multifactorial disease and its pathogenesis is still obscure. Epidemiological studies have demonstrated that interaction of environmental factors and genetic factors has

\footnotetext{
*Correspondence: dyyyjxk@mail.xjtu.edu.cn

Wenjing Zou and Xu Li are Co-first author.

${ }^{1}$ Department of gastroenterology, First Affiliate Hospital of Xi'an JiaoTong University, \#227 West Yanta Road, Xi'an 710061, Shaanxi Province, China
} Full list of author information is available at the end of the article been found to contribute to the risk of gastric cancer. Studies have shown that the first-degree relatives of gastric cancer patients tend to have about 1.3 to 3.0 fold higher relative risk for gastric cancer than those without relatives with gastric cancer [3].

MicroRNAs (miRNAs) are a class of important noncoding RNAs that play a biological role by inhibiting the expression of their targets at the post-transcriptional level. MiRNAs are involved in a variety of cellular processes, from embryonic development and immunity to carcinogenesis, by interacting with their multiple targets [4]. MiRNAs also play a vital role in the pathogenesis of gastric cancer $[5,6]$. MicroRNA-155 (miR-155) is a multifunctional miRNA that is involved in many disease processes including hematopoietic development $[7,8]$,

(C) The Author(s). 2020 Open Access This article is distributed under the terms of the Creative Commons Attribution 4.0 International License (http://creativecommons.org/licenses/by/4.0/), which permits unrestricted use, distribution, and 
inflammatory responses $[9,10]$, autoimmune [11], and tumorigenesis [12, 13]. However, the function of miR155 in gastric cancer has not been fully elucidated. MiR155 is a transcription product of its host gene (MIR155HG), and its expression may be affected by genetic variations of the MIR155HG gene.

Single nucleotide polymorphisms (SNPs) are the most common types of genetic variations that affect the risk of disease by altering the expression of related genes. To our knowledge, there were three studies have reported the relationship between MIR155HG SNPs and multiple sclerosis [14], atopic eczema [15], and epilepsy [16]. However, the exact relation between MIR155HG SNPs and gastric cancer risk is still undetermined.

Therefore, in this study, we conducted a case-control study among the Chinese Han population to clarify the relationship between MIR155HG SNPs and the risk of gastric cancer. Our results will help to understand the occurrence and development of gastric cancer from the perspective of molecular genetics, thus providing a theoretical basis for the early detection of gastric cancer.

\section{Methods}

\section{Subjects}

A total of 506 gastric cancer patients and 500 healthy controls were recruited at the Shaanxi Provincial Cancer Hospital. All the individuals were genetically unrelated ethnic northwest Han Chinese and all patients were diagnosed with gastric cancer by pathological analysis. We excluded the patients who received palliative surgery, preoperative treatment, or with incomplete pathological data. Subjects had no history of hereditary or malignant diseases. The clinical features of patients were collected from the patients' medical records provided, including age, gender, and clinical indicators. All individuals were informed of the purpose and experimental procedures of the study.

\section{DNA extraction and SNP genotyping}

Peripheral blood samples $(5 \mathrm{~mL})$ were collected from each subject. Genomic DNA was extracted from blood samples using the GoldMag-Mini Purifcation Kit (GoldMag Co. Ltd., Xi'an, China). The concentration and quality of the DNA were measured on a Nanodrop 2000 spectrophotometer (Thermo Scientific, USA). Seven SNPs with minor allele frequencies (MAFs) $>5 \%$, referenced from the 1000 Genomes database (http://www. internationalgenome.org/), were selected for subsequent analysis. Agena MassARRAY Assay Design Software (version 3.0, Agena Bioscience, San Diego, CA, USA) was used to design multiplexed SNP MassEXTEND assay. Agena MassARRAY RS1000 was used to detect SNP genotyping. Data management and analysis were conducted using Agena Software (version 4.0, Agena, San Diego, CA, USA) [17, 18].

\section{Statistical analyses and bioinformatics analysis}

The Hardy-Weinberg Equilibrium (HWE) was tested by using Fisher's exact test in the healthy control group. The odds ratios (ORs), 95\% confidence intervals (CIs) and $p$-values were calculated with the logistic regression model to assess the risk of gastric cancer. Four models (genotype, dominant, recessive, and additive) were used to assess the association between each genotype and the risk of gastric cancer [19]. The Haploview software package (version 4.2) and SHEsis software platform were used to analyze the pairwise linkage disequilibrium (LD), haplotype construction, and genetic association of polymorphism loci. SPSS software (version 22.0; SPSS Inc., Chicago, IL, USA) was used for all statistical analyses. All $p$-values were two-sided, and the adjusted $p$-value of less than 0.05 was considered to be significant.

HaploReg v4.1 (https://pubs.broadinstitute.org/mammals/haploreg/haploreg.php) was employed to predict the potential functions of the candidate SNPs.

\section{Results \\ Demographic and clinical characteristics}

The characteristics of gastric cancer patients shown in Table 1. The total of 506 patients ( 380 males, 126 females) with the average age of $61.11 \pm 0.50$ and 500 agematched healthy people (376 males, 124 females) with the mean age of $60.31 \pm 0.44$ were enrolled. There was no significant difference in age and gender distribution between the case and the control group $(p>0.05)$. In addition, the variance analysis of all the clinical indicators among patients with the different genotypes of selected SNPs shown in the Additional file 1: Table S1.

\section{The basic information of selected SNPs}

The basic information of the seven SNPs in MIR155HG shown in Table 2, including gene, chromosome, position, alleles, MAF in cases and controls and functional effects. All these SNPs complied with Hardy-Weinberg equilibrium in the control group. Additionally, we used HaploRegv4.1 to annotate the functional elements containing these selected SNPs. The results showed that the SNPs of MIR155HG were involved in the regulation related to DNAase, mark the promoter histone, change motifs, GRASP QTL hits, enhance histones, and bind proteins, suggesting they might exert biology functions in these ways in gastric cancer.

\section{SNPs and the risk of gastric cancer}

In Table 2, there was no significant association in allele frequency between cases and controls compared by $x^{2}$ test. Then, four inheritance models (genotype model, 
Table 1 Characteristics of the study population

\begin{tabular}{|c|c|c|c|}
\hline & Cases & Controls & $p$ \\
\hline Total & 506 & 500 & \\
\hline Age & & & $0.229^{a}$ \\
\hline Mean \pm SD & $61.11 \pm 0.50$ & $60.31 \pm 0.44$ & \\
\hline Sex & & & $0.970^{b}$ \\
\hline Male & $380(75 \%)$ & $376(75 \%)$ & \\
\hline Female & $126(25 \%)$ & $124(25 \%)$ & \\
\hline \multicolumn{4}{|l|}{ Stage } \\
\hline$|-| \mid$ & 105 (21\%) & & \\
\hline III-IV & $238(47 \%)$ & & \\
\hline Absence & $163(32 \%)$ & & \\
\hline \multicolumn{4}{|l|}{ LNM } \\
\hline Negative & $234(46 \%)$ & & \\
\hline Positive & 96 (19\%) & & \\
\hline Absence & $176(35 \%)$ & & \\
\hline \multicolumn{4}{|c|}{ CEA (0-20 ng/ml) } \\
\hline Mean \pm SD & $16.82 \pm 10.21$ & & \\
\hline \multicolumn{4}{|c|}{ SF (20-240 ng/ml) } \\
\hline Mean \pm SD & $89.05 \pm 8.19$ & & \\
\hline \multicolumn{4}{|c|}{ TNF (0.74-1.74fmol/ml) } \\
\hline Mean \pm SD & $1.01 \pm 2.08$ & & \\
\hline \multicolumn{4}{|c|}{ CA-50 (0-25 U/ml) } \\
\hline Mean \pm SD & $6.92 \pm 11.30$ & & \\
\hline \multicolumn{4}{|c|}{ CA-199 (0-37 U/ml) } \\
\hline Mean \pm SD & $39.70 \pm 76.36$ & & \\
\hline \multicolumn{4}{|c|}{ CA-242 (0-20KU/ml) } \\
\hline Mean \pm SD & $13.85 \pm 27.57$ & & \\
\hline \multicolumn{4}{|c|}{ AFP $(0-20 \mathrm{ng} / \mathrm{ml})$} \\
\hline Mean \pm SD & $12.08 \pm 15.33$ & & \\
\hline
\end{tabular}

$S D$ standard deviation, $L N M$ lymph node metastasis, CEA carcino-embryonic antigen, $S F$ serum ferritin, $T N F$ tumor necrosis factor, $\overline{C A}$ carbohydrate antigen, AFP alpha-fetoprotein

a $p$ values were calculated from independent sample $t$-test

${ }^{\mathrm{b}} p$ values were calculated from two-sided $x^{2}$ test

dominant model, recessive model, and additive model) were applied for analysing the association between each SNP and gastric cancer risk by logistic regression analysis adjusted for age and gender (Table 3). The result indicated that the "CC" genotype of rs4143370 was associated with a decreased risk of gastric cancer in genotype model $(\mathrm{OR}=0.37,95 \% \mathrm{CI}=0.16-0.86, p=0.020)$ and recessive model $(\mathrm{OR}=0.37,95 \% \mathrm{CI}=0.16-0.85, p=0.018)$, respectively. Inversely, the "CC" genotype of rs 1893650 was associated with an increased risk of gastric cancer in genotype model $(\mathrm{OR}=2.01,95 \% \mathrm{CI}=1.10-3.65, p=$ $0.023)$ and recessive model $(\mathrm{OR}=2.10,95 \% \mathrm{CI}=1.16$ $3.80, p=0.014)$.
Stratified analysis by gender revealed the relationship of MIR155HG-rs11911469 with gastric cancer risk and the results were exhibited in Table 4. We found that rs11911469 was associated with an increased risk of gastric cancer only in the male group under the dominant model $(\mathrm{OR}=1.45,95 \% \mathrm{CI}=1.02-$ 2.07, $p=0.039)$ and additive model $(\mathrm{OR}=1.45,95 \%$ $\mathrm{CI}=1.04-2.02, p=0.030$ ).

\section{Haplotype analysis}

The haplotype association analysis was based on six SNPs of MIR155HG (rs4143370, rs77699734, rs119114 69, rs1893650, rs34904192 and rs928883) (Table 5). We observed strong linkage disequilibrium among these six SNPs (Fig. 1). Whereas the results did not provide any statistical evidence of the associations between the haplotypes and gastric cancer risk in the subsequent analysis (all $p$-values were greater than 0.05 ).

\section{Discussions}

In the present study, selected SNPs in MIR155HG and their association with gastric cancer were investigated for the first time. Three MIR155HG variants (rs4143370, rs1893650, and rs11911469) were associated with the risk of gastric cancer among the Chinese Han population.

MIR155HG was found to be a marker of early stage cancer development [20]. MIR155HG gene is activated by MYB transcription factor and thus up-regulated, which in turn leaded to down-regulation of many tumor suppressor genes [21]. Previous studies have shown that three SNPs (rs2829803, rs2282471, rs2829806) of MIR155HG were associated with the risk of multiple sclerosis, and two SNPs (rs969885, rs987195) of MIR155HG in epilepsy were identified as the genetic susceptibility factors $[14,16]$. In this study, three novel SNPs (rs4143370, rs1893650, and rs11911469) were found to significantly affect the gastric cancer susceptibility. Our results suggest a great potential of MIR155HG in the early diagnosis of gastric cancer. For many years, intron sequences have been considered essentially non-functional. However, subsequent study showed that intron-containing genes presented higher levels of transcription when compared to intron-less genes in mammalian cells [22], suggesting that introns may be enhancers of transcription. In addition, we hypothesized that the genetic variation of MIR155HG gene may influence the expression of its transcription product miR-155, thus affecting its function in tumors. Stratified analysis found that MIR155HG-rs11911469 was associated with an increased risk of gastric cancer only in the male group. This result may be due to the presence of some gender-specific genes in the target genes of miR- 
Table 2 Basic information of candidate single nucleotide polymorphism (SNPS) in the study

\begin{tabular}{|c|c|c|c|c|c|c|c|c|c|c|}
\hline \multirow[t]{2}{*}{ SNP ID } & \multirow[t]{2}{*}{ Genes } & \multirow[t]{2}{*}{ Chr. } & \multirow[t]{2}{*}{ Position } & \multirow{2}{*}{$\begin{array}{l}\text { Alleles } \\
\text { A/B }\end{array}$} & \multicolumn{2}{|l|}{ MAF } & \multirow[t]{2}{*}{$p-H W E^{a}$} & \multirow[t]{2}{*}{$p^{\mathbf{b}}$} & \multirow[t]{2}{*}{$\mathrm{OR}(95 \% \mathrm{Cl})$} & \multirow[t]{2}{*}{ HaploReg } \\
\hline & & & & & Case & Control & & & & \\
\hline rs4143370 & MIR155HG & chr21 & $25,564,661$ & $C / G$ & 0.156 & 0.175 & 0.087 & 0.255 & $\begin{array}{l}0.87 \\
(0.69-1.10)\end{array}$ & $\begin{array}{l}\text { Promoter histone marks, Enhancer histone marks, } \\
\text { DNAse, Proteins bound, Motifs changed, Selected } \\
\text { eQTL hits }\end{array}$ \\
\hline rs77218221 & MIR155HG & chr21 & $25,565,063$ & $C / T$ & 0.042 & 0.056 & 0.662 & 0.131 & $\begin{array}{l}0.73 \\
(0.48-1.10)\end{array}$ & $\begin{array}{l}\text { Promoter histone marks, Enhancer histone marks, } \\
\text { Motifs changed }\end{array}$ \\
\hline rs77699734 & MIR155HG & chr21 & $25,566,995$ & $\mathrm{C} / \mathrm{G}$ & 0.096 & 0.092 & 0.293 & 0.778 & $\begin{array}{l}1.04 \\
(0.77-1.41)\end{array}$ & $\begin{array}{l}\text { Promoter histone marks, Enhancer histone marks, } \\
\text { DNAse, Proteins bound }\end{array}$ \\
\hline rs11911469 & MIR155HG & chr21 & $25,567,971$ & $\mathrm{~A} / \mathrm{C}$ & 0.127 & 0.103 & 0.339 & 0.089 & $\begin{array}{l}1.27 \\
(0.96-1.67)\end{array}$ & $\begin{array}{l}\text { Promoter histone marks, Enhancer histone marks, } \\
\text { DNAse, Proteins bound, Motifs changed }\end{array}$ \\
\hline rs1893650 & MIR155HG & chr21 & $25,568,503$ & $C / T$ & 0.189 & 0.174 & 0.535 & 0.391 & $\begin{array}{l}1.10 \\
(0.88-1.39)\end{array}$ & $\begin{array}{l}\text { Promoter histone marks, Enhancer histone marks, } \\
\text { DNAse, Proteins bound, Motifs changed, GRASP QTL } \\
\text { hits, Selected eQTL hits }\end{array}$ \\
\hline rs34904192 & MIR155HG & chr21 & $25,569,623$ & $A / G$ & 0.252 & 0.266 & 0.423 & 0.473 & $\begin{array}{l}0.93 \\
(0.76-1.14)\end{array}$ & $\begin{array}{l}\text { Promoter histone marks, Enhancer histone marks, } \\
\text { DNAse, Proteins bound, Motifs changed, Selected } \\
\text { eQTL hits }\end{array}$ \\
\hline rs928883 & MIR155HG & chr21 & $25,571,713$ & $A / G$ & 0.435 & 0.460 & 0.785 & 0.256 & $\begin{array}{l}0.90 \\
(0.76-1.08)\end{array}$ & $\begin{array}{l}\text { Enhancer histone marks, DNAse, Proteins bound, } \\
\text { Motifs changed, Selected eQTL hits }\end{array}$ \\
\hline
\end{tabular}

SNP single nucleotide polymorphism, MAF minor allele frequency, HWE Hardy-Weinberg equilibrium, OR odds ratio, 95\% CI 95\%confidence interval

${ }^{a}$ HWE $p^{a}$-value were calculated from Fisher's exact test

${ }^{\mathrm{b}} p$ values were calculated from two-sided $x^{2}$ test

155. But these internal connections need to be verified by subsequent functional experiments.

In recent years, a large number of studies have shown that miR-155, as an oncomiR, plays a vital role in carcinogenesis. Upregulated mir-155 levels have been found in many solid malignancies [23]. In colorectal cancer, the expression of miR-155-5p was upregulated. It has been proved that high expression of miR-155-5p promoted the proliferation, invasion and metastasis of colorectal cancer cells [24]. In addition, upregulation of mir-155 has been reported to be associated with poor prognosis in lung cancer and breast cancer $[25,26]$. In contrast, several studies have revealed that mir-155 may act as a tumor-suppressor in some cancers. Mir-155

Table 3 Analysis of association between rs4143370 and rs1893650 polymorphism and risk of gastric cancer

\begin{tabular}{|c|c|c|c|c|c|c|c|c|}
\hline \multirow[t]{2}{*}{ SNP ID } & \multirow[t]{2}{*}{ Model } & \multirow[t]{2}{*}{ Genotype } & \multirow[t]{2}{*}{ Case $(N)$} & \multirow[t]{2}{*}{ Control( $(M)$} & \multicolumn{2}{|l|}{ Crude } & \multicolumn{2}{|l|}{ Adjusted $^{a}$} \\
\hline & & & & & $\mathrm{OR}(95 \% \mathrm{Cl})$ & $p^{\dagger}$ & $\mathrm{OR}(95 \% \mathrm{Cl})$ & $p^{+}$ \\
\hline \multirow[t]{8}{*}{ rs4143370 } & \multirow[t]{3}{*}{ Genotype } & GG & 356 & 346 & 1 & & & \\
\hline & & GC & 142 & 133 & $1.04(0.79-1.37)$ & 0.795 & $1.04(0.79-1.37)$ & 0.794 \\
\hline & & CC & 8 & 21 & $0.37(0.16-0.85)$ & $0.019^{*}$ & $0.37(0.16-0.86)$ & $0.020^{*}$ \\
\hline & \multirow[t]{2}{*}{ Dominant } & GG & 356 & 346 & 1 & & 1 & \\
\hline & & GC-CC & 150 & 154 & $0.95(0.72-1.24)$ & 0.690 & $0.94(0.72-1.24)$ & 0.698 \\
\hline & \multirow[t]{2}{*}{ Recessive } & GG-GC & 498 & 479 & 1 & & 1 & \\
\hline & & CC & 8 & 21 & $0.37(0.16-0.84)$ & $0.017^{*}$ & $0.37(0.16-0.85)$ & $0.018^{*}$ \\
\hline & Additive & - & - & - & $0.87(0.69-1.10)$ & 0.258 & $0.88(0.69-1.11)$ & 0.266 \\
\hline \multirow[t]{8}{*}{ rs1893650 } & \multirow[t]{3}{*}{ Genotype } & $\pi$ & 350 & 343 & 1 & & & \\
\hline & & TC & 121 & 140 & $0.85(0.64-1.13)$ & 0.254 & $0.85(0.64-1.13)$ & 0.261 \\
\hline & & $\mathrm{CC}$ & 35 & 17 & $2.02(1.11-3.67)$ & $0.021 *$ & $2.01(1.10-3.65)$ & $0.023^{*}$ \\
\hline & \multirow[t]{2}{*}{ Dominant } & $\pi$ & 350 & 343 & 1 & & 1 & \\
\hline & & TC-CC & 156 & 157 & $0.97(1.75-1.27)$ & 0.845 & $0.97(0.75-1.27)$ & 0.852 \\
\hline & \multirow[t]{2}{*}{ Recessive } & Tा-TC & 471 & 483 & 1 & & 1 & \\
\hline & & CC & 35 & 17 & $2.11(1.17-3.82)$ & $0.014^{*}$ & $2.10(1.16-3.80)$ & $0.014^{*}$ \\
\hline & Additive & - & - & - & $1.09(0.88-1.35)$ & 0.419 & $1.09(0.88-1.35)$ & 0.421 \\
\hline
\end{tabular}

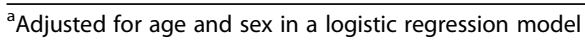

${ }^{\dagger} p$ values were calculated from wald test

*Bold values indicate statistical significance $(p<0.05)$ 
Table 4 Stratification analysis of the association of MIR155HG polymorphisms with gastric cancer by gender

\begin{tabular}{|c|c|c|c|c|c|c|}
\hline \multirow[t]{2}{*}{ SNP ID } & \multirow[t]{2}{*}{ Model } & \multirow[t]{2}{*}{ Genotype } & \multicolumn{2}{|l|}{ Male } & \multicolumn{2}{|l|}{ Female } \\
\hline & & & OR(95\%Cl) & $p^{+}$ & OR(95\%Cl) & $p^{\dagger}$ \\
\hline \multirow[t]{8}{*}{ rs11911469 } & Genotype & AA & 1 & & & \\
\hline & & $A C$ & $1.42(0.99-2.03)$ & 0.058 & $0.86(0.48-1.55)$ & 0.626 \\
\hline & & CC & $2.66(0.51-13.85)$ & 0.245 & $1.93(0.17-12.62)$ & 0.595 \\
\hline & Dominant & AA & 1 & & 1 & \\
\hline & & $A C-C C$ & $1.45(1.02-2.07)$ & $0.039 *$ & $0.89(0.51-1.60)$ & 0.713 \\
\hline & Recessive & $A A-A C$ & 1 & & 1 & \\
\hline & & CC & $2.48(0.48-12.88)$ & 0.280 & $1.99(0.18-22.29)$ & 0.576 \\
\hline & Additive & - & $1.45(1.04-2.02)$ & $0.030^{*}$ & $0.95(0.55-1.61)$ & 0.835 \\
\hline
\end{tabular}

${ }^{\dagger} p$ values were calculated from wald test

*Bold values indicate statistical significance $(p<0.05)$

expression was down-regulated in melanoma and ovarian cancer and significantly inhibited tumor growth in vivo and in vitro $[27,28]$. In addition, Wang et al. found that deficiency mir-155 significantly promoted tumor growth and metastasis in bone marrow-derived inhibitory cells [29]. Similarly, up to now, the reports about miR-155 expression and its role in gastric cancer have been inconsistent. Previous studies reported that the expression of miR-155 was significantly up-regulated and acted as a tumor-promoter in gastric cancer, while another literature suggested that miR-155 was one of the most downregulated miRNAs, which may play a role in inhibiting tumor in gastric cancer [30,31]. In addition, mir-155 levels were found to be lower in patients with advanced gastric cancer and higher in patients with early gastric cancer [32]. These inconsistent conclusions may be caused by different sources of experimental samples and need to be verified in the future. Although the detailed mechanism of mir-155 in gastric cancer remains to be further explored, it may be a suitable choice for the early diagnosis of gastric cancer patients as a biomarker.

Table 5 Haplotype frequencies of MIR155HG SNPs and the association with gastric cancer

\begin{tabular}{|c|c|c|c|c|}
\hline \multirow[t]{2}{*}{ Haplotype } & \multicolumn{2}{|c|}{ Haplotype Frequency } & \multirow[t]{2}{*}{$\mathrm{OR}(95 \% \mathrm{Cl})$} & \multirow[t]{2}{*}{$p^{+}$} \\
\hline & Case & Control & & \\
\hline \multicolumn{5}{|c|}{ rs4143370|rs77699734|rs11911469|rs1893650|rs34904192|rs928883 } \\
\hline _GCATGA_ & 0.568 & 0.548 & $1.09(0.91-1.29)$ & 0.367 \\
\hline _GGATAG_ & 0.904 & 0.910 & $0.94(0.70-1.27)$ & 0.689 \\
\hline _CCATAG_ & 0.156 & 0.174 & $0.88(0.70-1.12)$ & 0.298 \\
\hline _GCACGG_ & 0.189 & 0.172 & $1.11(0.89-1.37)$ & 0.353 \\
\hline _GCCTGG_ & 0.874 & 0.896 & $0.80(0.60-1.06)$ & 0.116 \\
\hline
\end{tabular}

OR odds ratio, $95 \% \mathrm{Cls} 95 \%$ confidence intervals

${ }^{\dagger} p$ values were calculated by logistic regression with adjustment for age and gender
However, we considered that there are some limitations in this study. First, this study was conducted only in the Chinese Han population. Due to differences in regional environment and genetic background, the function of these SNPs in other ethnic groups is worth considering. Second, gastric cancer is a complex disease affected by a variety of inherited and environmental factors. We should not ignore the influence of the interaction between genetic polymorphism and environmental factors on gastric cancer susceptibility.

\section{Conclusions}

To sum up, our study confirmed the relationship between SNPs of MIR155HG and the risk of gastric cancer

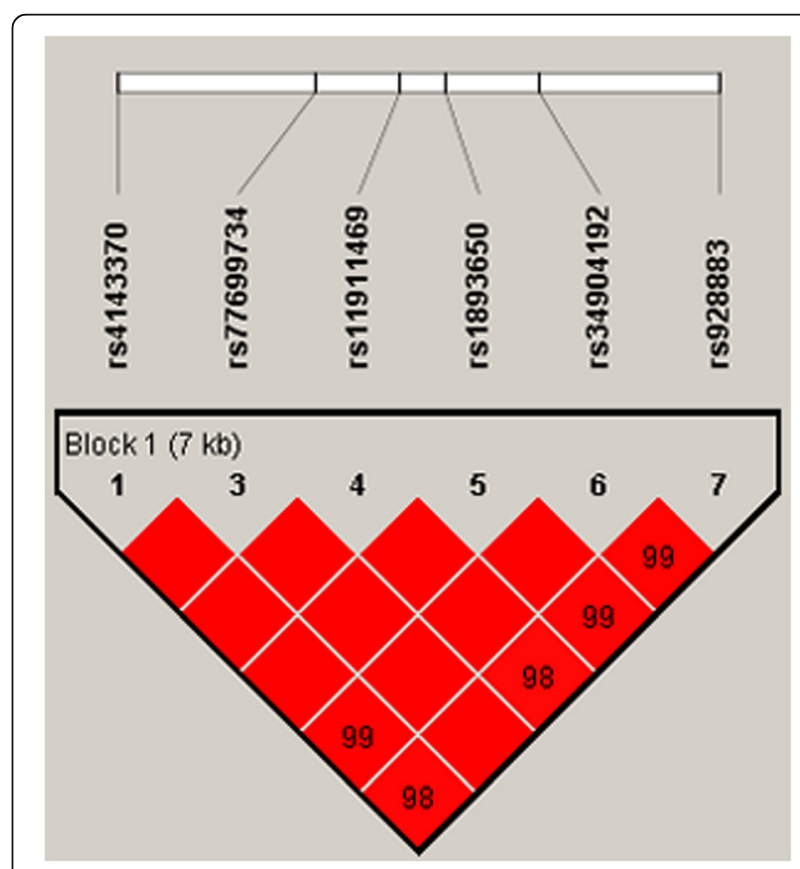

Fig. 1 Haplotype block map for the SNPs in MIR155HG gene. The numbers inside the diamonds indicate the $D^{\prime}$ for pairwise analyses 
among the Chinese Han population. We hope that this study can provide a new and promising strategy for the early detection of gastric cancer and provide the possibility for the early prevention of this disease. Further studies will increase the sample size and clinical data, as well as carry out functional studies and repeated in different ethnic groups.

\section{Supplementary information}

Supplementary information accompanies this paper at https://doi.org/10 1186/s12876-020-1169-8.

Additional file 1: Table S1. Variance analysis of clinical characteristics among patients and different genotypes of SNPS

\section{Abbreviations}

Cl: Confidence interval; HWE: Hardy-Weinberg Equilibrium; LD: Linkage disequilibrium; MAF: Minor allele frequency; miRNA: MicroRNA; OR: Odds ratios; SNP: Single nucleotide polymorphism

\section{Acknowledgments}

We thank the physicians and medical staff of the Shaanxi Provincial Cancer Hospital for their contributions and support of this work. We are grateful to all participants for providing blood samples.

\section{Authors' Contributions}

SX H carried out the studies, data analyses and drafted the manuscript. WJ Z and $X L$ participated in the design of the study and performed the statistical analysis. $C L, D L$ and $Y Y L$ conceived of the study and participated in its design and coordination and helped draft the manuscript. N Y and G D designed, coordinated. YY supervised the study and critically reviewed and discussed the manuscript. All authors have read and approved the final version of the manuscript.

\section{Funding}

This research received no specific grant from any funding agency in the public, commercial, or not-for-profit sectors.

\section{Availability of data and materials}

The datasets used and analyzed in the current study are available from the corresponding author on reasonable request.

\section{Ethics approval and consent to participate}

The study described was approved by the Shaanxi Provincial Cancer Hospital ethics committee. All procedures performed in studies involving human participants were in accordance with the 1964 Helsinki declaration and its later amendments or comparable ethical standards. All participants were informed in writing and verbally of the procedures and purpose of this study, and signed written informed consent forms.

\section{Consent for publication}

Not Applicable.

\section{Competing interests}

The authors declare that they have no conflict of interest.

\section{Author details}

${ }^{1}$ Department of gastroenterology, First Affiliate Hospital of Xi'an JiaoTong University, \#227 West Yanta Road, Xi'an 710061, Shaanxi Province, China. ${ }^{2}$ Department of The fifth of Internal Medicine, Xi'an No5 Hospital, Xi'an 710082, Shannxi, China. ${ }^{3}$ Department of The First of Internal Medicine, Tumor Hospital of Shannxi Province, The Affiliate Hospital of Medical College of Xi'an JiaoTong Univrsity, Xi'an 710061, Shannxi, China. ${ }^{4}$ Department of Geriatrics, Xi'an Central Hospital, Xi'an 710003, Shannxi, China. ${ }^{5}$ Department of Rheumatology, Xi'an No5 Hospital, Xi'an 710082, Shannxi, China. ${ }^{6}$ Department of The Second of Internal Medicine, Xi'an No5 Hospital, Xi'an 710082, Shannxi, China.
Received: 10 June 2019 Accepted: 13 January 2020

Published online: 20 January 2020

\section{References}

1. Fitzmaurice C, Dicker D, Pain A, Hamavid H, Moradi-Lakeh M, Maclntyre MF, et al. The global burden of cancer 2013. JAMA Oncology. 2015;1(4):505-27.

2. Chen W, Zheng R, Baade PD, Zhang S, Zeng H, Bray F, et al. Cancer statistics in China, 2015. CA Cancer J Clin. 2016;66(2):115-32.

3. Hemminki K, Sundquist J, Ji J. Familial risk for gastric carcinoma: an updated study from Sweden. Br J Cancer. 2007;96(8):1272

4. Ha M, Kim VN. Regulation of microRNA biogenesis. Nat Rev Mol Cell Biol. 2014;15(8):509.

5. Parizadeh S, Jafarzadeh-Esfehani R, Avan A, Ghandehari M, Goldani F. The prognostic and predictive value of microRNAs in patients with $\mathrm{H}$. pyloripositive gastric cancer. Curr Pharm Des. 2018;24(39):4639-45. https://doi. org/10.2174/1381612825666190110144254.

6. Hu M, Zhu S, Xiong S, Xue X, Zhou X. MicroRNAs and the PTEN/PI3K/Akt pathway in gastric cancer. Oncol Rep. 2019;41(3):1439-54.

7. Georgantas RW, Hildreth R, Morisot S, Alder J. Liu C-g, Heimfeld S, et al. CD34+ hematopoietic stem-progenitor cell microRNA expression and function: a circuit diagram of differentiation control. Proc Natl Acad Sci. 2007:104(8):2750-5.

8. O'Connell RM, Rao DS, Chaudhuri AA, Boldin MP, Taganov KD, Nicoll J, et al. Sustained expression of microRNA-155 in hematopoietic stem cells causes a myeloproliferative disorder. J Exp Med. 2008;205(3):585-94.

9. O'Connell RM, Taganov KD, Boldin MP, Cheng G, Baltimore D. MicroRNA-155 is induced during the macrophage inflammatory response. Proc Natl Acad Sci. 2007:104(5):1604-9.

10. Hu R, Kagele DA, Huffaker TB, Runtsch MC, Alexander M, Liu J, et al. miR-155 promotes $T$ follicular helper cell accumulation during chronic, low-grade inflammation. Immunity. 2014;41(4):605-19.

11. Hu R, Huffaker TB, Kagele DA, Runtsch MC, Bake E, Chaudhuri AA, et al. MicroRNA-155 confers encephalogenic potential to Th17 cells by promoting effector gene expression. J Immunol. 2013;190(12):5972-80.

12. Jiang $\mathrm{S}$, Zhang H-W, Lu M-H, He X-H, Li Y, Gu H, et al. MicroRNA-155 functions as an OncomiR in breast cancer by targeting the suppressor of cytokine signaling 1 gene. Cancer Res. 2010;70(8):3119-27.

13. Li C-L, Nie H, Wang M, Su L-P, Li J-F, Yu Y-Y, et al. microRNA-155 is downregulated in gastric cancer cells and involved in cell metastasis. Oncol Rep. 2012;27(6):1960-6.

14. Paraboschi EM, Soldà G, Gemmati D, Orioli E, Zeri G, Benedetti MD, et al. Genetic association and altered gene expression of mir-155 in multiple sclerosis patients. Int J Mol Sci. 2011;12(12):8695-712.

15. Sääf A, Kockum I, Wahlgren C-F, Xu N, Sonkoly E, Ståhle M, et al. Are BIC (miR-155) polymorphisms associated with eczema susceptibility? Acta Derm Venereol. 2013:93(3):366-7.

16. Tao H, Cui L, Li Y, Zhou X, Ma G, Yao L, et al. Association of tag SNPs and rare CNVs of the MIR155HG/miR-155 gene with epilepsy in the Chinese Han population. Biomed Res Int. 2015;2015:837213. https://doi.org/10.1155/2015/ 837213. Epub 2015 Sept 6.

17. Yuan $L$, Jin TB, Yin JK, Du XL, Wang Q, Dong R, et al. Polymorphisms of tumor-related genes IL-10, PSCA, MTRR and NOC3L are associated with the risk of gastric cancer in the Chinese Han population. Cancer Epidemiol. 2012:36(6):e366-e72

18. He N, Liu L, Duan X, Wang L, Yuan D, Jin T, et al. Identification of a shared protective genetic susceptibility locus for colorectal cancer and gastric cancer. Tumor Biol. 2016;37(2):2443-8.

19. Zhang K, Civan J, Mukherjee S, Patel F, Yang H. Genetic variations in colorectal cancer risk and clinical outcome. World J Gastroenterol: WJG. 2014:20(15):4167.

20. Thiele J-A, Hosek P, Kralovcova E, Ostasov P, Liska V, Bruha J, et al. IncRNAs in Non-Malignant Tissue Have Prognostic Value in Colorectal Cancer. Int J Mol Sci. 2018:19(9):2672.

21. Nielsen CB, Shomron N, Sandberg R, Hornstein E, Kitzman J, Burge CB. Determinants of targeting by endogenous and exogenous microRNAs and siRNAs. Rna. 2007;13(11):1894-910.

22. Vaz-Drago R, Custodio N, Carmo-Fonseca M. Deep intronic mutations and human disease. Hum Genet. 2017;136(9):1093-111.

23. Chen Z, Ma T, Huang C, Hu T, Li J. The pivotal role of microRNA-155 in the control of cancer. J Cell Physiol. 2014;229(5):545-50. 
24. Qu Y-L, Wang H-F, Sun Z-Q, Tang Y, Han X-N, Yu X-B, et al. Up-regulated miR-155-5p promotes cell proliferation, invasion and metastasis in colorectal carcinoma. Int J Clin Exp Pathol. 2015;8(6):6988.

25. Yanaihara N, Caplen N, Bowman E, Seike M, Kumamoto K, Yi M, et al. Unique microRNA molecular profiles in lung cancer diagnosis and prognosis. Cancer Cell. 2006;9(3):189-98.

26. Kong W, He L, Richards E, Challa S, Xu C, Permuth-Wey J, et al. Upregulation of miRNA-155 promotes tumour angiogenesis by targeting VHL and is associated with poor prognosis and triple-negative breast cancer Oncogene. 2014;33(6):679.

27. Levati L, Pagani E, Romani S, Castiglia D, Piccinni E, Covaciu C, et al. MicroRNA-155 targets the SKI gene in human melanoma cell lines. Pigment Cell Melanoma Res. 2011;24(3):538-50

28. Qin W, Ren Q, Liu T, Huang Y, Wang J. MicroRNA-155 is a novel suppressor of ovarian cancer-initiating cells that targets CLDN1. FEBS Lett. 2013;587(9): 1434-9.

29. Wang J, Yu F, Jia X, Iwanowycz S, Wang Y, Huang S, et al. Micro RNA-155 deficiency enhances the recruitment and functions of myeloid-derived suppressor cells in tumor microenvironment and promotes solid tumor growth. Int J Cancer. 2015;136(6):E602-E13.

30. Kim BH, Hong SW, Kim A, Choi SH, Yoon SO. Prognostic implications for high expression of oncogenic microRNAs in advanced gastric carcinoma. Surg Oncol. 2013;107(5):505-10.

31. Li H, Xie S, Liu M, Chen Z, Liu X, Wang L, et al. The clinical significance of downregulation of mir-124-3p, mir-146a-5p, mir-155-5p and mir-335-5p in gastric cancer tumorigenesis. Int J Oncol. 2014:45(1):197-208.

32. Ma Z, Ma Y, Xia Q, Li Y, Li R, Chang W, et al. MicroRNA-155 expression inversely correlates with pathologic stage of gastric cancer and it inhibits gastric cancer cell growth by targeting cyclin D1. J Cancer Res Clin Oncol. 2016;142(6):1201-12

\section{Publisher's Note}

Springer Nature remains neutral with regard to jurisdictional claims in published maps and institutional affiliations.

Ready to submit your research? Choose BMC and benefit from:

- fast, convenient online submission

- thorough peer review by experienced researchers in your field

- rapid publication on acceptance

- support for research data, including large and complex data types

- gold Open Access which fosters wider collaboration and increased citations

- maximum visibility for your research: over $100 \mathrm{M}$ website views per year

At $\mathrm{BMC}$, research is always in progress.

Learn more biomedcentral.com/submissions 